ARTICLE HISTORY: July: 19, 2021 Accepted: September 12, 2021 Published: September 19, 2021

УДК 621.6:622.69

ОСНОВНЫЕ ПРОБЛЕМЫ ТРУБОПРОВОДНОГО ТРАНСПОРТА УГЛЕВОДОРОДОВ

\author{
Тянь Ифань \\ Магистр \\ Санкт-Петербургский Горный Университет,
}

\title{
MAINPROBLEMS OF PIPELINE TRANSPORTATION OF HYDROCARBONS
}

\author{
Tian Yifan \\ Master degreestudent, \\ Saint Petersburg Mining University
}

\begin{abstract}
Аннотация. В работе приводятся основные проблемы трубопроводного транспорта углеводородов в условиях специфичных грунтов, в частности многолетнемерзлых грунтов, так как на сегодняшний день стратегическим тылом экономического развития Российской Федерации представляется топливноэнергетическая база области вечной мерзлоты.Было выявлено, что срок эксплуатации и надежность конструкций коррелируют с естественным состоянием мерзлоты и грунта в области основания сооружения. Также было обнаружено, что наземная прокладка магистрального трубопровода для транспорта углеводородов позволяет сократить частоту их отказов и выходов из строя.

Summary. The paper presents the main problems of pipeline transportation of hydrocarbons in conditions of specific soils, in particular permafrost soils, since today the strategic rear of the economic development of the Russian Federation is the fuel and energy base of the permafrost region. the state of permafrost and soil in the area of the base of the structure. It was also found that laying the main pipeline on the ground for transporting hydrocarbons can reduce the frequency of their failures and breakdowns.

Ключевые слова: магистральный трубопровод, транспорт углеводородов, многолетнемерзлые грунты, наземная прокладка, подземная прокладка

Key words: main pipeline, transportation of hydrocarbons, permafrost, surface laying, underground laying
\end{abstract}

По состоянию на 2021 г. мировые энергоемкие производства развиваются активными темпами, из чего вытекает, что уже к 2050 г. областями жизнедеятельности человека будет потребляться в 2 раза больше энергии. На данный момент стремительно осваиваются нефтегазоносные провинции северных территорий, которые расположены территориально удаленно от центральных районов переработки и дальнейшего потребления основных типов углеводородного топлива: природного газа и нефти. Это обуславливает актуальность топливной проблемы, которая определяется объемами их добычи и дальнейшего трубопроводного транспорта[8].

На сегодняшний день стратегическим тылом экономического развития Российской Федерации представляется топливно-энергетическая база области вечной мерзлоты. Согласно данных проведенных исследований, в данной области сосредоточено свыше $35 \%$ разведанных государственных нефтезапасов и свыше $60 \%$ природного газа[5]. Помимо этих ценных ресурсов в данной области также выявлены масштабные залежи торфа и каменного угля. Это обуславливает актуальность изучения основных проблем трубопроводного транспорта углеводородов в условиях мерзлоты для их эффективного разрешения в перспективе.

Российская Федерации имеет большой опыт в сфере транспортировки углеводородов на значительные расстояния посредством трубопроводов. Однако эксплуатация трубопроводного транспорта в условиях области вечной мерзлоты продемонстрировала на практике, что чем ближе центры добычи углеводородов к областям многолетнемерзлыхгрунтов, тем больше количество задач и вопросов, которые необходимо устранять, при этом ряд возникающих проблем требуют оперативного разрешения непосредственно в ходе строительства трубопровода. Необходимо учитывать, что отсутствие качественного и своевременного изучения и рассмотрения данного класса проблем в последующем ведет к трудностям в ходе эксплуатации магистралей и реализации трубопроводного транспорта углеводородов.

Недостаточный уровень изученности проблем трубопроводного транспорта углеводородов не позволяет обеспечивать надежность и бесперебойную работоспособность магистральных трубопроводов, протяженность которых измеряется тысячами километров. Таким образом, в текущих условиях в регионах арктического шельфа, Восточной Сибири и Крайнего Севера эффективный трубопроводный транспорт углеводородов возможен только при условии применения высокотехнологичного инновационного оборудования, нестандартных конструкторских решений и высокоэффективных современных технологий низкой энергоемкости. 
Рассматривая проблему трубопроводного транспорта углеводородов в условиях вечной мерзлоты как одну из главных и открывающую большие перспективы для развития данной отрасли, необходимо учитывать, что мерзлые грунты характеризуются совокупностью специфичных особенностей, которые объясняют необратимые реакции в ходе техногенных воздействий при возведении и дальнейшей эксплуатации трубопроводов для транспорта углеводородов.

Техногенное вмешательство, обусловленное возведением и дальнейшей эксплуатацией трубопроводов для транспорта углеводородов, неразрывно связано с нарушением естественного хода природных криогенных процессов и постепенному повышению теплоты в мерзлых грунтах. Как результат грунты выпучиваются, проседают и частично теряют устойчивость, что негативно сказывается на состоянии инфраструктуры, возведённые объекты для промысла нефтепродуктами и газом, а также магистральные трубопроводы для транспорта углеводородов разрушаются под действием перечисленных факторов.

В связи с этим стратегической задачей на стадии разработки проекта трубопровода является создание условий, позволяющих регулировать и минимизировать оказываемое на мерзлоту воздействие тепла посредством подбора оптимального способа прокладки магистрали и должного регламента ее дальнейшего использования в созданных условиях для решения поставленных задач.

В данном направлении необходимо отметить развитие и активное использование сегодня специализированных укреплений для основ возведенных трубопроводных сооружений посредством внедрения трубчатых систем, которые характеризуются промораживающим естественным действием. К данным системам относятся термостабилизирующая система грунтов «ГЕТ», вертикальная естественно действующая трубчатая система «ВЕТ», система обнаружения утечек «СОУ».

Российские предприятия могут похвастаться налаженным серийным производством специализированных термостабилизаторов, свай и опор для конструкций, задействованных в трубопроводном транспорте углеводородов, а также производством резервуаров, труб и оборудования, которые характеризуются высокими теплоизоляционными свойствами. На данный момент производство перечисленных изделий осуществляется на базе 20 предприятий[12].

Перечисленные и другие конструкции и технологии были использованы в процессе создания таких трубопроводов для транспорта углеводородов как:

- Пурпе -Самотлор.

- Куюмба-Тайшет.

- 3 Заполярье - НПС - Пурпе

Особого внимания заслуживает последний магистральный трубопровод. Его совокупная протяженность составляет 483 км, из которых 169 км проложены под землей. Для его возведения была организовано свыше 19 тысяч специализированных опор только для участков, которые проходят над землей. Совокупная протяжённость участков, которые пролегают под землей составляет 316 км, что составляет более $1 / 2$ всего трубопровода. Чтобы сократить до минимума оказываемое на зону вечной мерзлоты воздействие, было организовано 23 вертельных резервуара из высоколегированной стали над землей, которые базируются на фундаментах свайного типа. Важно учитывать, что в резервуарах предусмотрены стабилизация тепла грунтового основания и подполье с системой вентиляции [9].

Применение специализированных устройств, основной задачей которых является промораживание грунта с целью стабилизации как сооружений площадок, так и самих магистральных трубопроводов, является на сегодняшний день перспективным вектором, что объясняется его соответствием принципу сведения оказываемого теплового воздействия к минимуму. Однако практическая реализация диктует необходимость дальнейшего совершенствования как самих используемых конструкций и сооружений, так и режимов процесса промораживания. Это объясняется тем, что в ходе использования промораживающих устройств различных видов прямым образом нарушается основополагающий принцип не вторжения и не нарушения естественного текущего состояния грунта.

При организации трубопроводного транспорта углеводородов и решения существующих проблем отрасли, необходимо следовать данному принципу. Это продиктовано тем, что монтаж устройств, которые оказывают промораживающее действие и работают только в определенные периоды, сезоны, нарушает естественное равновесие термодинамического баланса грунта, на котором они организуются.

Проведенные на сегодняшний день исследования продемонстрировали, что искусственно наведенные бугры пучения могут быть следствием промораживания грунта [7].

Решением рассмотренных проблем может статьи соблюдения принципа наименьшего вторжения в естественный грунт. Данный принцип на данный момент не учтен и не зафиксирован в нормативно-правовой базе, регламентирующей магистральный трубопроводный транспорт углеводородов $[10,11]$. Однако данный принцип описан и подробно обоснован в ряде современных исследований $[1,2,4,6]$.

Перечисленные исследования были реализованы в условиях многолетнемерзлых грунтов таких регионов как Тикси, Воркута, Игарка, а также в условиях северных магистральных трубопроводов с Ямбарского 
месторождения, локализованного на территории Западной Сибири. Было выявлено, что срок эксплуатации и надежность конструкций коррелируют с естественным состоянием мерзлоты и грунта в области основания сооружения: минимальная степень нарушения ведет к максимальной долговечности и надежности возведенных сооружений.

Также было выявлено, что наземная прокладка магистрального трубопровода для транспорта углеводородов позволяет сократить частоту их отказов и выходов из строя. Помимо этого, наземная прокладка повышает работоспособность магистрали. В частности, было выявлено, что интенсивность участков, пролегающих по различным территориям выглядит следующим образом:

- Интенсивность отказов на участках с наземной прокладкой -0.13 ;

- Интенсивность отказов на участках с надземной прокладкой, в том числе над торфяниками, суглинками и т.д. - от 0.5 до 0.6

- Интенсивность отказов на участках с подземной прокладкой - свыше 3[13].

На основании проанализированных исследований сегодня можно говорить о том, что наиболее рациональным методом монтажа магистральных трубопроводов для транспорта углеводородов в условиях торфяных и многолетнемерзлых грунтов в соответствии с принципом наименьшего вторжения в естественный грунт являются следующие методы прокладки:

1. Открытая прокладка магистрали по поверхности с организацией специализированного конверта для изоляции тепла.

2. Прокладка без ликвидации покрова из мха.

3. Прокладка с погружением с замерзшей поверхности.

Наземный способ прокладки магистрального трубопровода для транспорта углеводородов по мерзлому грунту, который не нарушается, представляет собой наиболее выгодный с экономической точки зрения способ. Он открывает перспективы для минимизации оказываемых негативных последствий техногенного действия и позволяет максимально сохранить структуру грунту, участка мерзлоты.

Также одной из проблем является технологическое регулирование обмена тепла между грунтом и магистральным трубопроводом в процессе транспорта углеводородов. В рассматриваемых условиях необходимо регулировать размеры талика, который протекает вокруг трубопровода, что реализуется посредством контроля и регулирования интенсивности оказываемого трубопроводом действия тепла на естественное состояние грунта. Анализ исследований показал, что для обеспечения безопасной эксплуатации магистрального трубопровода для транспорта углеводородов необходимо контролировать наличие небольшого, но стабильного талика вокруг трубопровода. Это объясняется тем, что в случае полного смерзания грунта, трубопровод защемляется, а в случае повышения напряжения деформируется и разрывается.

Соблюдение рассчитанного теплогидравлического режима дает возможность предупредить развитие таянье грунта под магистральным трубопроводов, что позволяет сделать процесс контролируемым. Для расчета и разработки режима учитываются такие показатели как сбалансированная температура перекачки углеводородов и производительность трубопровода. Расчет теплогидравлического режима для магистральных трубопроводов при этом базируется на методе смены стационарных состояний и реализуется по алгоритму, выработанному практическим путем [3].

Таким образом, грунты чувствительны к техногенному воздействию, оказываемому в ходе трубопроводного транспорта углеводородов, что проявляется изменением их механических, тепловых и физических характеристик. На сегодняшний день актуально изучение проблем сложных процессов, которые протекают в грунте вокруг магистрального трубопровода для транспорта углеводородов и объясняются фазовыми метаморфозами влаги, содержащейся в грунте. Из этого вытекает необходимость аналитического решения задач взаимодействия трубопроводов и грунтов, особенно мерзлых грунтов в ходе различных технологических процессов. Это станет фундаментом для нового вектора в области трубопроводного транспорта углеводородов.

\section{Литература:}

1. Гаррис Н.А., Акчурина Э.А., Бахтизин Р.Н. Сопряженная задача теплообмена с инжекцией холода с поверхности земли. SOCARProceeding, 2018, № 2, p. 025-032.

2. Гаррис Н.А., Закирова Э.А. Третий принцип использования мерзлых грунтов в качестве основания трубопроводов. Территория «Нефтегаз». 2017. № 5. С. 70-78.

3. Гаррис Н.А., Кутлыева 3.Р. Алгоритм регулирования процесса протаивания-промерзания грунта вокруг наземного трубопровода в условиях вечной мерзлоты. Нефтегазовое дело. 2018. Т. $16 . \quad$ № 6. C. 46-55.

4. Гаррис Н.А., Полетаева О.Ю., Бакиев Т.А. Проблемы трубопроводного транспорта углеводородов в условиях мерзлоты и пути их решения. Транспорт и хранение нефтепродуктов. 2020. №3. URL: https://cyberleninka.ru/article/n/problemy-truboprovodnogo-transporta-uglevodorodov-v-usloviyah-merzloty-i-puti-ihresheniya (дата обращения: 31.07.2021). 
5. Гаррис Н.А., Русаков А.И., Лебедева А.А. Расчет сбалансированного теплообмена нефтепровода в мерзлоте и определение радиуса ореола протаивания. Нефтегазовое дело. 2018. Т. 16. № 5. С. 73-80.

6. Димов Л.А. Строительство нефтепроводов на многолетнемерзлых грунтах в южной части криолитозоны Центральной и Восточной Сибири. Нефтяное хозяйство. 2008. № 2. С. 104-106.

7. Закирова Э.А., Гаррис Н.А. Как избежать выпучивания опор надземных трубопроводов в районах пучинистых грунтов. Нефтегазовое дело. 2016. Т. 14. № 2. С. 85-92.

8. Леонтьев А.Ю., Полетаева О.Ю., Бабаев Э.Р., Мамедова П.Ш. Влияние СВЧ-воздействия на изменение вяз кости высоковязких тяжелых нефтей. НефтеГазоХимия, 2018. № 2. С. 25-27.

9. Лисин Ю.В., СапсайА.Н., Суриков В.И. и др. Создание и реализация инновационных технологий строительства в проектах развития нефтепроводной структуры Западной Сибири (проекты «Пурпе - Самотлор», «Заполярье - Пурпе») // Наука и технологии трубопроводного транспорта нефти и нефтепродуктов, 2013. № 4 (12). C. 6-11.

10. СП 25.13330.2012 Основания и фундаменты на вечномерзлых грунтах.

11. СП 36.13330.2012 Магистральные трубопроводы.

12. Термостабилизация вечномерзлых грунтов https://www.npo-fsa.ru/proizvodstvo(дата обращения 31.07.2021).

13. ХарионовскийВ.В. Надежность и ресурс конструкций газопроводов. М.: Недра, 2001. 467 с. 